\title{
The Treatment of Clear Cell Ovarian Cancer with the Poly (ADP- Ribose) Polymerase (PARP1) Inhibitors (AG14361,Veliparib,Olaparib) as Chemosensitizers.
}

\section{Joseph Angel de Soto}

${ }^{1}$ School of Science, Technology, Engineering and Math, Dine College, Tsaile AZ 86566

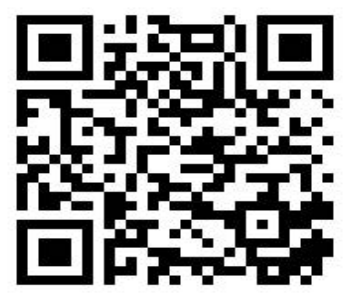

\section{1 | INTRODUCTION}

$\mathrm{T}$ The American Cancer Society and National Cancer Institute estimates that there will be over 22,240 new cases of ovarian cancer with over 14,000 deaths from ovarian cancer this year. (1) The median age for diagnosis for sporadic disease is 60 years with those with a genetic tendency towards ovarian cancer often being diagnosed in their 50's. Ovarian cancer represents tumors of epithelial, germ cell and sex cord-stromal origin. Epithelial ovarian cancer which arises from arise from the surface epithelium of the ovary represents about $90 \%$ of ovarian cancers. The most important risk factors for the development of ovarian cancer are age, family history and infertility while lactation, pregnancy, and tubal ligation are mildly protective. (2) The ovarian epithelium cancers can be divided into four types: papillary serous, endometroid, mucinous and clear cell. Clear cell represents represent $6 \%$ of the 
epithelial cells types and is the most aggressive and resistant to therapy. (3) Following cytoreductive surgery for ovarian cancer the use of platinum taxane based chemotherapy has traditionally been the gold standard for chemotherapy. (1) Although most ovarian cancers are chemosensitive at diagnosis drug acquired resistance frequently appears leading to progression and ultimately death.

The hallmark of cancer development is the development of clonal expansions genetic mutations which continue to accrue additional genetic mutations and eventually genomic instability. This led to the idea that perhaps one could take advantage of this genetic instability in cancer cells an instability not present in non-cancer cells. (4) Thus, providing a pathway to targeted therapy. In a paper by Farmer that appeared in Nature, the feasibility of using PARP inhibitors as targeted therapy was shown. (5) It has reported that cells with BRCA1 or BRCA2 mutations which are important for homologous recombination were 1000 times more sensitive to PARP inhibition than those cell without a defect in homologous recombination. (6) Papers by De Soto and another by Calabrese illustrated the clinical feasibility of using PARP inhibitors as chemosensitizers in the treatment of human cancer. $(7,8)$ Poly (ADP-Ribose) Polymerase (PARP) is a key enzyme utilized in the repair of single strand DNA damage via the Base Excision Repair pathway. PARP inhibition produces persistent single-strand DNA breaks which during mitosis become double stranded breaks at the replication fork. (9) These double stranded breaks may be repaired by homologous recombination. However, many cancers are deficient in their ability to repair by homologous recombination due to deficiencies in BRCA1, BRCA2 and other enzymes needed in this repair pathway. This leads to the accumulation of chromosomal damage and the death of cancer cells. Because most non-cancer cells are efficient in

Supplementary information The online version of this article (https://doi.org/10.15520/jemro.v3i11.36 2) contains supplementary material, which is available to authorized users.

Corresponding Author: Joseph Angel de Soto

School of Science, Technology, Engineering and Math, Dine College, Tsaile AZ 86566 homologous recombination, they are relatively unaffected by the inhibition of PARP. Myelosuppression however dies occur with PARP inhibitors in addition to somnolence. $(10,11)$ Today, PARP inhibitors are approved for maintenance therapy in ovarian cancer following platinum based therapy. (12) PARP inhibitors are also treatment friendly as Olaparib and Veliparib both have the advantage of being available orally. $(13,14)$ Here we show the effective use of PARP inhibiters as chemosensitizers against clear cell carcinoma with taxane, platinum and other agents used to treat ovarian cancer.

\section{2 | MATERIALS \& METHODS}

\section{Cell Lines \& Medications}

ES-2, TOV-112D, TOV-21G, and SKOV-3 and human epithelial ovarian cancer cell lines where obtained from American Type Tissue Culture in Manassas VA. Cisplatin, Carboplatinum, Doxorubicin, 5-Fluorouracil, Gemcitabine and Paclitaxel where purchased from Sigma-Aldrich, St. Louis MO. The PARP-1 inhibitor AG14361 was obtained from Organix inc. in Woburn MA while ABT888 (Veliparib) and AZD2281 (Olaparib) were obtained from Selleck Chemical in Houston TX. Cells were grown in DMEM media with $10 \%$ fetal bovine serum in a $5 \%$ $\mathrm{CO}_{2}$ incubator at $37{ }^{0} \mathrm{C}$. Cells at $80-85 \%$ confluence were trypsinized, washed with PBS and plated for each experiment

\section{Determining IC50 Values}

Standard curves where made by plating $25 \mathrm{k}$ to $300 \mathrm{k}$ cells for each cell line for 4-12 hours and after ascertaining that the cells where attached exposed to a solution of $1 \mathrm{mg} / \mathrm{ml}$ thiazolyl blue tetrazolium (MTT) for 30 minutes. This was followed by decanting the MTT and adding propranolol to each well for 30 minutes. The absorption for each well was read with the Perkin-Elmer 1420 multi-label counter. Each data point was replicated at least 10 times. IC50 values were then determined by plating cells in 12 well plates and after incubation for 4-12 hours the cells were exposed for 72 hours to various doses of 
drug. There were at least two controls containing vehicle for each experiment. The number of cells in each well at each specific drug concentration was then determined by the previously described MTT assay. Each experiment was replicated at least 9 times with the tenth time being a direct cell count by hemacytometer. The IC 50 values were then calculated by graphing the \% inhibition vs $\log ($ dose $)$ using Sigma Plot and standard 3rd order (sigmoidal) equations with the required $\mathrm{r} 2$ value having to be $>$ 0.975 .

The "PARP in vivo Pharmacodynamic Assay II kit" from Trevigen inc, Gaithersburg MD was used to determine the amount of PARP activity in each cell line prior to and after treatment with PARP inhibitors.

\section{3 | RESULTS}

The IC50 values of AG14361, Veliparib and Olaparib against clear cell, serous and mucinous epithelial ovarian cancer cell lines was evaluated. The ES-2 clear cell ovarian carcinoma was derived from a 47 year old African American female with low to moderate level resistance to cisplatin and doxorubicin. (15) This clear ovarian cancer was very sensitive to PARP inhibition with the IC50 values for AG14361, Veliparib and Olaparib being $6.2 \mu \mathrm{M}$, $38 \mu \mathrm{M}$ and $97 \mu \mathrm{M}$. A second clear cell ovarian carcinoma TOV21G was derived from a 62 year old female was also found to be very sensitive to PARP inhibition. (16) The following are the IC50 values of the PARP inhibitors against the TOV21G ovarian cancer cell line: AG14361 $8.9 \mu \mathrm{M}$, Veliparib $78 \mu \mathrm{M}$ and Olaparib $150 \mu \mathrm{M}$. A serous ovarian cancer cell line SKOV-3 derived from a 64 year old female with tumor resistance to cisplatin and doxorubicin was tested against AG14361, Veliparib and Olaparib with the IC50 values being $15.2 \mu \mathrm{M}, 82 \mu \mathrm{M}$ and $17.6 \mu \mathrm{M}$. The Ov-90 cell line was another serous cell ovarian cancer cell line evaluated which was derived from a 64 year old French female. (17) The OV-90 cell line is Her2/neu + and like the clear cell line TOV-
$21 \mathrm{G}$ has a deletion at $3 \mathrm{p} 24$. Interestingly, this same locus has been found to be associated with breast cancer. The IC50 values for the Ov-90 cell line were $5.2 \mu \mathrm{M}, 35 \mu \mathrm{M}$ and $15 \mu \mathrm{M}$ for AG14361, Veliparib and Olaparib respectively. Next the ability of the PARP inhibitors to inhibit endometrioid type ovarian cancer was evaluated through the TOV112D ovarian cancer cell line. This cell line was derived from a 42 year old French female and was her $2 /$ neu + . (16) The IC50 values after exposure to the PARP inhibitors were similar to those obtained for the serous cell lines the results are summarized in Table 1.

Evidence suggests that the PARP inhibitors may be able to chemo- sensitize breast and brain cancers to DNA damaging agents. The IC50 values for five commonly used chemotherapeutic agents used to treat ovarian cancer cisplatin, carboplatin, doxorubicin, 5-fluorouracil, gemcitabine and paclitaxel where determined for the ES-2, TOV112D and TOV21G cell lines Table 2 . Next, we determined the IC50 value of these same agents when used in combination with a constant $10 \mu \mathrm{M}$ of AG14361. The value of $10 \mu \mathrm{M}$ was chosen as it is a blood level which represents a blood level which might clinically be reached not only for AG14361 but Veliparib and Olaparib, thus potentially allowing for the translation of these results into the clinic.

\section{4 | DISCUSSION}

It has been shown that up to $50 \%$ of ovarian cancers may have trouble repairing double strand breaks via homologous recombination. (18) The addition of adjuvant chemotherapy in clear cell carcinoma does not show any survival difference following surgical excision in stage I and stage II cancer and little improvement in stage III or IV. (19) Thus, the need for improved cytotoxicity of adjuvant chemotherapy towards clear cell ovarian cancer is needed. Clear cell ovarian cancer has been compared to triple negative breast cancer due to its absence of both estrogen and progesterone receptors and rapid growth. (20) Dysfunctional homologous recombination is a deter- 
minant in platinum and PARP sensitivity and possibly taxane sensitivity providing a rational for the use of PARP inhibitors in conjunction with these other agents in treating ovarian cancer. (21) Loss of the ability to perform homologous recombination may be due to either genetic mutation or epigenetic influences. (22) The increased amount of double stranded breaks leads to rapid chromosomal instability and cellular death. Among the proteins that may have mutations or be epigenetically silenced are BRCA1, BRCA2, PALB2, ATM, CHEK1, CHEK2, and RAD51. (23) The loss of homologous recombination is also associated with TP53 mutation and hence, a loss of cell cycle regulation. (24) Which may be important in clear cell ovarian cancer which is an exceptionally fast growing cancer. Additionally, PARP may act as a chemosensitizer by also partially disrupting spindle assembly. (25) PARP inhibitors may be especially useful for those cancers that are resistant to prior platinum and other treatments but, are limited in their ability to chemosensitize these agents in cancers that are refractory to specific chemoagents (26) . Refractory behavior is often seen in ovarian cancer that has a back mutation in previously dysfunctional enzymes needed for homologous recombination. (27) The use of PARP inhibitors may also be useful in treating those clear cell carcinomas that are cross resistant to platinum, topoisomerase and ionizing radiation therapy providing a grim outcome for these patients. This type of cross resistance is often due elevated glutathione-S-transferase which detoxifies these agents. (15) The use of PARP inhibitors would allow for a cytotoxic effect for the reduced levels of chemotherapeutic agents.

The use of PARP inhibitors maybe useful as single agent maintenance therapy in clear cell carcinoma as the sensitivity to PARP is at least as great as serous cell ovarian cancer which has been shown to be amiable to maintenance therapy. (28)

\section{5 | CONCLUSION}

The use of PARP inhibitors to treat clear cell ovarian cancer in conjunction with platinum agents, taxane or topoisomerase inhibitors may allow for using a lower dose of these toxic agents and thus reduce the side effects. Additionally, the use of PARP inhibitors as chemosensitizers may allow for the more targeted and efficient killing of clear cell ovarian cancer cells. PARP inhibitors are exceptional chemosensitizers of clear cell ovarian cancer to treatment with most standard chemotherapy agents. Gemcitabine however is however antagonized by PARP inhibitors. This is the first paper to specifically show the effectiveness of PARP inhibitors against clear cell ovarian cancer.

\section{REFERENCES}

1) De Vita V, Lawrence $T$, Rosenberg $S$ (2019). Cancer Principles \& Practice of Oncology, Wolters Kluwer Publishers.

2) Reid BM, Permuth JB, Sellers TA. Epidemiology of ovarian cancer: a review, Cancer Biol Med, 2017;14(1):9-32.

3) Yamashita Y. Ovarian cancer: new developments in clear cell carcinoma and hopes for targeted therapy. Japanese Journal of Clinical Oncology 2015;45(5):405-407.

4) Mateo J, Lord CJ, Serra V, Tutt A, Balmana $\mathrm{J}$, et al. A decade of clinical development of PARP inhibitors in perspective. Annals of Oncology DOI: 10.1093/anon/mdz192.

5) Farmer $H$, McCabe $N$, Lord CJ, Tutt A, Johnson DA. Targeting the DNA repair defect in BRCA mutant cells as a therapeutic strategy. Nature 2005 Apr 14;434(7035):917-21.

6) Fong PC, Yap TA, Boss DS, Tutt A., Wu P, et al. Poly(ADP-ribose) polymerase inhibition: Frequent durable responses in BRCA carrier correlating with platinum -free survival. JCO 2010;28:2512-2519.

7) De Soto JA, Wang $X$, Tominaga $Y$ et al. (2006). The inhibition of treatment of breast cancer with poly(ADP-ribose) polymerase (PARP-1) inhibitors. Int. J. Biol. Sci. 2006;2(4):179-185. 
8) Calabrese CR, Almassy R, Barton S, et al. Anticancer chemosensitization and radiosensitization by the novel poly(ADPribose) polymerase-1 inhibitor AG14361. J Natl Cancer Inst. 2004;96:56-67.

9) McCabe N, Lord CJ, Tutt AN, Martin NM, Smith G, et al. BRCA2-deficient CAPAN-1 cells are extremely sensitive to the inhibition of Poly (ADP-Ribose) polymerase: an issue of potency. Cancer Biol Ther 2005 Sep;4(9):934-6. doi: 10.4161/cbt.4.9.2141

10) Spriggs DR, Longo DL. PARP Inhibitors in Ovarian Cancer Treatment. NEJM 2016 DOI 10.10.1056/NEJMe1612843.

11) Underhill $C$, Toulmonde $M$, Bonnefoi H. A review of PARP inhibitors: from bench to bedside. Ann Oncol. 2010 Jul 19.

12) Moore KN, Pothuri B, Monk B, Coleman RL. PARP inhibition in recurrent ovarian cancer. Clinical advances in hematology \& Oncology. 2020;18:10

13) Campos SM, Ghosh S. A current review of targeted therapeutics for ovarian cancer. J. Oncology 2010:2010;149362.

14) Kummar S, Kinders R, Gutierrez ME, et al. Phase 0 clinical trial of the poly(ADP-Ribose) polymerase inhibitor ABT-888 in patients with advanced malignancies.

JCO 2009;27:2705-2711.

15) Lau DH, Lewis $A D$, Ehsan $M N$, et al. Multifactorial mechanisms associated with broad cross-resistance of ovarian carcinoma cells selected by cyanomorpholino doxorubicin. Cancer Res. 1991; 51:5181-7.

16) Provencher DM, Lounis H, Champoux L, et al. Characterization of four novel epithelial cancer cell lines. In Vitro Cell. Dev. Biol. Anim. 36: 357-361, 2000.
17) Lounis H, Mes-Masson AM, Dion F et al. Mapping of chromosome $3 p$ deletions in human epithelial ovarian tumors. Oncogene 17: 2359-2365, 1998.

18) Mukhopathy A, Elattar A, Cerbinskaite A. Development of a functional assay for homologous recombination status in primary cultures of epithelial ovarian tumor and correlation with sensitivity to poly(ADP-ribose) polymerase inhibitors. Clin Canc Res 2010;16:2344-2351.

19) Lee HY, Hong JH, Byun JH, Kim HJ, Baek SK. Clinical characteristics of clear cell ovarian cancer: A retrospective multicenter experience of 308 patients in South Korea. Cancer Res Treat. 2020 Jan;52(1):277-283.

20) Nagasawa S, Ikeda K, Horie-Inoue K, et al. Systematic Identification of characteristic genes of ovarian clear cell Carcinoma compared with high grade serous carcinoma based on RNA sequencing. International Journal of Molecular Sciences. 2019 Sep; 20(18): 4330.

21) Gentles L, Goranov B, Matheson, et al. Exploring the frequency of homologous recombination DNA repair dysfunction in multiple cancer types. Cancers 2019 Mar; 11(3): 354.

22) Press JZ, De Luca A, Boyd N. Ovarian carcinomas with genetic and epigenetic BRCA1 loss have distinct molecular abnormalities. BMC Cancer 2008:8:17-28.

23) Papa A, Caruso D, Strudel M et al., Update on Poly-ADP-ribose polymerase inhibition for ovarian cancer treatment. Journal of Translational Medicine. 2016;14:267.

24) Hennessy BT, Timms KM, Carey MS et al., Somatic mutations in BRCA1 and BRCA2 could expand the number of patients that benefit from poly(ADP-ribose) polymerase inhibitors in ovarian cancer. JCO 2010;28:3570-3576. 


\section{CURRENT MEDICAL RESEARCH AND OPINION}

25) Chang P, Jacobson MK, Mitchison TJ. Poly(ADP-ribose) is required for spindle assembly and structure. Nature 2004;432:645-649.

26) Gien LT, Mackay HJ. The emerging role of PARP inhibitors in the treatment of epithelial ovarian cancer. J Oncol. 2010;2010:151750.

27) Swisher EM, Sakai W, Karlan BY, et al. Secondary BRCA1 mutations in BRCA1mutated ovarian carcinomas with platinum resistance. Cancer Res 2008;68:2581-2886.

28) Ledermann J, Harter P, Gourley C, Friedlander M, Vergote I, et al. Olaparib maintenance in platinum - sensitive relapsed ovarian cancer. 2012;366:1382-92.
How to cite this article: Soto J.A. The Treatment of Clear Cell Ovarian Cancer with the Poly (ADP- Ribose) Polymerase (PARP1) Inhibitors (AG14361,Veliparib,Olaparib) as Chemosensitizers. . Journal of Current Medical Research and Opinion. 2020;732-738.

https://doi.org/ 10.15520/jcmro.v3i11.360 


\section{THE TREATMENT OF CLEAR CELL OVARIAN CANCER WITH PARP INHIBITORS}

TABLE 1: The IC50 values ofselected PARP inhibitors against sporadic epithelial ovarian cancer

\begin{tabular}{llll}
$\begin{array}{l}\text { Cell Line } \\
\text { Subtype }\end{array}$ & $\begin{array}{l}\text { AG14361 } \\
\text { IC50 }\end{array}$ & $\begin{array}{l}\text { Veliparib } \\
\text { IC50 }\end{array}$ & $\begin{array}{l}\text { Olaparib } \\
\text { IC50 }\end{array}$ \\
$\begin{array}{l}8.9 \mu \mathrm{M} \\
\text { TOV21G } \\
\text { Clear Cell }\end{array}$ & $78 \mu \mathrm{M}$ & $150 \mu \mathrm{M}$ \\
$\begin{array}{l}\text { ES-2 } \\
\text { Clear Cell }\end{array}$ & $6.2 \mu \mathrm{M}$ & $38 \mu \mathrm{M}$ & $97 \mu \mathrm{M}$ \\
$\begin{array}{l}\text { SKOV-3 } \\
\text { Serous } \\
\text { OV-90 } \\
\text { Serous }\end{array}$ & $15.2 \mu \mathrm{M}$ & $82.0 \mu \mathrm{M}$ & $17.6 \mu \mathrm{M}$ \\
$\begin{array}{l}\text { TOV112D } \\
\text { Endometrioid }\end{array}$ & $5.2 \mu \mathrm{M}$ & $35.0 \mu \mathrm{M}$ & $15.0 \mu \mathrm{M}$ \\
\hline
\end{tabular}

TABLE 2: The IC50 values ofselected chemotherapy agents against sporadic epithelial ovarian cancer

\begin{tabular}{llll} 
& ES-2 & TOV112D & TOV-21G \\
& Clear cell & Endometrioid & Serous \\
Cisplatin & $1.18 \mu \mathrm{M}$ & $5.4 \mu \mathrm{M}$ & $17.5 \mu \mathrm{M}$ \\
Doxorubicin & $0.046 \mu \mathrm{M}$ & $0.038 \mu \mathrm{M}$ & $0.082 \mu \mathrm{M}$ \\
5-Fluorouracil & $20.7 \mu \mathrm{M}$ & $19.9 \mu \mathrm{M}$ & $40.5 \mu \mathrm{M}$ \\
Gemcitabine & $0.00012 \mu \mathrm{M}$ & $0.0046 \mu \mathrm{M}$ & $8.6 \mu \mathrm{M}$ \\
Paclitaxel & $0.018 \mu \mathrm{M}$ & $0.008 \mu \mathrm{M}$ & $0.075 \mu \mathrm{M}$ \\
\hline
\end{tabular}

TABLE 3:

PARP inhibitor + Chemotherapeutic Agent

ES-2 Ovarian Cancer Cell Line (IC50 values)

\begin{tabular}{|c|c|c|c|c|c|c|}
\hline Drug & $+10 \mu \mathrm{M}$ AG14361 & $\Delta$ & $+10 \mu \mathrm{M}$ Veliparib & $\Delta$ & +10 $\mu \mathrm{M}$ Olaparib & $\Delta$ \\
\hline Cisplatin & $0.002 \mu \mathrm{M}$ & $590 x$ & $0.01 \mu \mathrm{M}$ & $118 x$ & $0.005 \mu \mathrm{M}$ & $235 x$ \\
\hline Carboplatin & $0.001 \mu \mathrm{M}$ & $18,800 x$ & $11.2 \mu \mathrm{M}$ & $1.7 x$ & $1 \mu \mathrm{M}$ & $18.8 x$ \\
\hline Doxorubicin & $0.00023 \mu \mathrm{M}$ & $200 x$ & $0.017 \mu \mathrm{M}$ & $2.7 x$ & $0.009 \mu \mathrm{M}$ & $5.1 x$ \\
\hline 5-Fluorouracil & $0.001 \mu \mathrm{M}$ & $20,700 x$ & $6.1 \mu \mathrm{M}$ & $3.4 x$ & $20.2 \mu \mathrm{M}$ & $1.02 x$ \\
\hline Gemcitabine & $0.00012 \mu \mathrm{M}$ & $1 x$ & $0.0028 \mu \mathrm{M}$ & $0.04 x$ & $0.0022 \mu \mathrm{M}$ & $0.054 x$ \\
\hline Paclitaxel & $0.018 \mu \mathrm{M}$ & $180 x$ & $0.043 \mu \mathrm{M}$ & $1.4 x$ & $0.0001 \mu \mathrm{M}$ & $600 x$ \\
\hline \multicolumn{7}{|c|}{ TOV-112D Cancer Cell Line (IC50 values) } \\
\hline Cisplatin & $0.1 \mu \mathrm{M}$ & $54 x$ & $3.8 \mu \mathrm{M}$ & $1.4 x$ & $1.0 \mu \mathrm{M}$ & $5.4 x$ \\
\hline Carboplatin & $42.0 \mu \mathrm{M}$ & $1.7 x$ & $70.0 \mu \mathrm{M}$ & $1 x$ & $50.0 \mu \mathrm{M}$ & $1.4 \mathrm{x}$ \\
\hline Doxorubicin & $0.013 \mu \mathrm{M}$ & $2.9 x$ & $0.018 \mu \mathrm{M}$ & $2.1 x$ & $0.031 \mu \mathrm{M}$ & $1.2 \mathrm{x}$ \\
\hline 5-Fluorouracil & $1.0 \mu \mathrm{M}$ & $19.9 x$ & $5.9 \mu \mathrm{M}$ & $3.4 x$ & $8.0 \mu \mathrm{M}$ & $2.5 x$ \\
\hline Gemcitabine & $0.03 \mu \mathrm{M}$ & $0.11 x$ & $0.01 \mu \mathrm{M}$ & $0.33 x$ & $0.038 \mu \mathrm{M}$ & $0.86 x$ \\
\hline Paclitaxel & $0.0008 \mu \mathrm{M}$ & $25 x$ & $0.013 \mu \mathrm{M}$ & $1.4 x$ & $0.0012 \mu \mathrm{M}$ & $15 x$ \\
\hline \multicolumn{7}{|c|}{ TOV21G (IC50 values) } \\
\hline 5-Fluorouracil & $0.001 \mu \mathrm{M}$ & $40,500 x$ & $6.8 \mu \mathrm{M}$ & $6 x$ & $28.0 \mu \mathrm{M}$ & $1.4 x$ \\
\hline Paclitaxel & $0.005 \mu \mathrm{M}$ & $14 x$ & $0.005 \mu \mathrm{M}$ & $4.4 x$ & $0.014 \mu \mathrm{M}$ & $1.5 x$ \\
\hline
\end{tabular}

